\title{
Geoffrey Hinchliffe
}

University of East Anglia

\section{POLITICS IN A SOCIETY OF CONTROL}

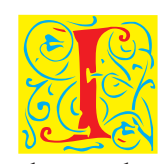

n a brief pamphlet written in 1992 Gilles Deleuze suggested that the disciplinary society was being replaced by the society of control (Deleuze, 1992). Whereas the disciplinary society was organised through institutional enclosures characterised by mechanisms of surveillance, measurement and the administration of life through instruction, prescription and monitoring, the society of control achieves the administration of life through procedures that take the form of codes, guidelines, and process. Rather than enclosures, it is characterised by an apparent openness. The hallmark of the society of control is the sheer ubiquity of the surveillance and self-surveillance of behaviour through the incessant calibration of behaviours through expectations, perceptions and norms of appropriateness. Whereas in a disciplinary society one could escape (if only temporarily) institutions, no one can escape the networks of relations in which one is enmeshed; nothing is ever finished, training is perpetual and the distinction between work and leisure is finally completely abolished. We could say that in the society of control, power is procedural and the most important kind of knowledge is also procedural - for it is through this kind of knowing that one can change behaviours, motivate individuals, secure funds and grasp the most important weapon of all: leverage over others.

The control society sets its face against the supposed discredited disciplinary society through the promise of freedom from directive supervision and the promise of control of one's life: but for Deleuze whilst these new mechanisms may appear attractive they never achieve their promise. Indeed, the new reality of control leads us to mock grand schemes of emancipation; now we are more mature we can learn to settle for much, much less and find satisfaction in mastering the procedures of our own ensnarement and in small, fleeting victories. 
In this situation, political discourse consists of the repeated evocation of empty signifiers that have no connection with the experience of control. We are familiar with them all: freedom from state control (that slogan is particularly mendacious), democracy, responsibility, "grown-up politics," "the return of power to where it belongs - the people," "our nation," etc. The "public" for which this discourse is intended exists on a virtual plane; this is a public of which all are members but whose voices are confined to impotent interventions - tweets, online comments, letters and blogs that remain unread. Above all, this public is a prisoner of the present, an empty present whose links to the past are characterised by historical cliché and antiquarian curiosity.

\section{Rationalisation}

It will be instructive to dwell a little more closely on the kind of control that Deleuze indicates. For we must be clear that it is not a control characterised by domination, that is, the purposeful domination of some individuals by others. Nor are these networks of control peculiar to the $21^{\text {st }}$ century - the modes of control, certainly, are recent, but its character was recognised at the beginning of the $20^{\text {th }}$ century by Max Weber. ${ }^{1}$ In his Protestant Ethic, Weber famously invokes the "iron cage," signifying the development of procedures and behaviours necessary for a modern economic order whilst "the rosy blush of its laughing heir, the Enlightenment, seems to be irretrievably fading" (Weber, 181-82). Jurgen Habermas provides us with a concise discussion and amplification of Weber's central thesis. According to Habermas, purposeful rationality includes: the development of techniques to reproduce predicted behaviours; the world so configured that the efficacy of such techniques become progressively easier to achieve; the privileging of ends which preclude ends chosen for affective reasons or relating to tradition; the unwillingness to grant rationality of value postulates or belief systems as regards their content; and, finally and crucially, the development of a methodical conduct and personality (Habermas, 168-71).

Habermas speaks of this form of rationality as "purposive rationality" but if we accept that any kind of practical conduct will have a purposive character then we need to describe this phenomenon in a different way. If the form of rationality described is characterised as "rationalisation" then we can see that it

\footnotetext{
1 For an overview, see Sica (2000).
} 
is rationalisation that gives us the "iron cage," and not rationality or reason as such. And it seems to me that we can amplify Habermas's account of rationalisation as follows:

a) In the giving and receiving of reasons what counts as a reason is conditioned by requirements of rationalisation and this therefore severely curtails communicative competence viewed as a free activity;

b) Rationalisation does not only disenchant nature but also disenchants those human activities connected with moral, aesthetic and even science because the values associated with those spheres are either nullified or become themselves rationalised, i.e. subject to procedural judgements in which content is underplayed;

c) Behaviours compliant with the imperatives of rationalisation are encouraged through status recognition and monetary reward (for example, pro-active behaviour). The price of non-conformity is non-recognition and irrelevance. One is expected to comport oneself in accordance with the injunctions of rationalisation so that they become a key part of one's identity;

d) Rationalisation is no longer neutral with respect to values but itself generates values appropriate to the process of rationalisation itself. The most significant of these is achievement and success; these are the goals - the ends of life - that individuals encourage in each other and in which they find the most satisfaction and happiness;

e) "change" itself becomes a positive value not only to be welcomed but to be deliberately brought about. In a culture of rationalisation there must be ceaseless activity and it is incumbent on those with authority to make sure their charges never become too comfortable. This extends not only to employees but also to electorates.

Rationalisation pervades political discourse not only in terms of characterising the means for securing goals; it increasingly characterises those goals themselves. Education, for example, is rationalised through the characterisation of learning as an achievement-process in which assessment lies at its heart. This amounts to more than the mere prizing of good results; the entire process itself is driven by a system of monitoring and evaluation at every stage in which teachers - not just pupils - are held to account. ${ }^{2}$ Moreover, the choices made by

2 A good example of the rationalisation of pedagogy is contained in a standard work of pedagogy addressed at university teachers in which the strategy of "constructive alignment" is commended, i.e. the alignment of learning outcomes, learning activities and assessment. This is termed by the authors a "web of consistency." See Biggs and Tang (2011). 
politicians in respect of education are themselves the choices of rationalisation - these are choices which are deliberately exercised and fostered. In the United Kingdom, at least, politicians - both left and right - are the champions of rationalisation. ${ }^{3}$

The process of rationalisation extends across a range of policy areas so that both the procedures and values of rationalisation are embedded in institutions and pervade the perspectives and practices of all those agents embroiled in them. It is for this reason that the mere invocation of alternate values have limited effect over and above rhetorical value. For the alternate values associated with, say, the Green movement, are themselves only embedded weakly and fitfully. It is interesting, as an aside, that even the traditional values of liberalism or, indeed, political conservatism, have also become rationalised. There is no modern conservative in the whole of Europe who any longer simply wants to conserve: the modern conservative is as much concerned to "drive change" as her liberal or socialist counterpart.

\section{Exploring alternatives}

Does the phenomenon of rationalisation derive from some defect of rationality so that the Enlightenment contains the seeds of its own undermining? The problem with this approach is that if rationality per se is deemed suspect then the alternatives must be held to originate in other spheres of activity, such as aesthetics. Yet aesthetics activity is as much beset by rationalisation as any other sphere of activity; one will not find any area of activity unsullied. If one is struck by the way in which solutions and strategies are deliberately chosen that involve rationalisation, then this phenomenon cannot be seen merely as the unfolding necessity of a Reason shorn from any context or traditions. For this species of rationality assuredly does have a context - namely the very culture of rationalisation that its activity generates. Thus a genealogical explanation seems preferable - to this extent one can then affirm the Weberian thesis that rationalisation had its origins in Protestant asceticism and that we are now living with the accumulative effects of instrumentalism, aided by the requirements of industrial organisation and associated technologies, not least the development of real-time communication.

3 For example, both Labour and Conservative politicians have implemented policies of perpetual assessment of pupils aged 5-18 even though alternatives have been clearly spelt out by teachers and educational researchers. 
Could it be argued that an alternative could be constructed by thinking afresh our communicative abilities in such a way that rationalisation is side-stepped? This is one way of viewing Habermas's theory of communicative competence. I take it that the idea is that communication (in the sense of the giving and asking for reasons) is seen as primary, that is, that communication "is" embedded in language, not that it ought to be. Rationalisation can then be seen as a deviation of language from its originary, communicative path. ${ }^{4}$ But whatever the merits of communicative action I do not think that its features can be read back into the structure of language in this way. Rather, language can be bent and fashioned to serve the cause of emancipation or repression equally. So, just as rationalisation has not developed through a path of necessity so there is no originary or foundational set of human activities that we can retrieve and use as a basis for a more emancipatory politics. Counteracting the culture and practice of rationalisation is a voluntary act.

But to say it is voluntary does not mean that one cannot draw on activities and discourses that do not have rationalisation at their core. What would such practices look like? Alasdair McIntyre provides us with one picture through conceiving activities in terms of practices. The idea here is that a practice generates its own goods and its own goals and purposes; therefore criteria of excellence are internal to that practice. In this way, it could be said that a practice generates its own rationale, independent of the demands of rationalisation. Macintyre's definition of a practice is well-known:

By a practice I mean any coherent and complex form of socially established cooperative human activity through which goods internal to that form of activity are realised in the course of trying to achieve those standards of excellence that are appropriate to, and partly definitive of, that form of activity, with the result that human powers to achieve excellence and human conceptions of the ends and goods involved are systematically extended. (MacIntyre, 175)

We can see how this might work, especially through the suggestion that a practice contains its own internal goods. These could be moral or ethical but they could also be aesthetic in the case of, say, the performing arts, or epistemological, in the case of, say, the sciences. It is not, of course, that practices, so understood, do not contain activities that are instrumental and rational-purposive: but these kinds of activities are subordinate to, and partly defined by, what con-

\footnotetext{
${ }^{4}$ For this succinct summary, see Rasmussen (1990).
} 
stitutes an internal good. Moreover, given that long established practices have long traditions, these may act as powerful counterweights to rationalisation. For through a tradition, the present can re-connect with the past so that traditions become part of the present. For example, for both musicians and appreciators of jazz, Miles Davis and Duke Ellington are never truly dead and their music forms part of a living tradition that any jazz musician has to address and understand. It is true, of course that the importance of tradition may vary from practice to practice and some practitioners may draw from only the recent past. But the point is that change is something that can be understood in terms of that practice since changes (new styles, new theories) are internally generated through engagement with that practice. In this sense, a practice may be seem as having its own genealogy with its own internal time-structure. That is, a practice can be viewed diachronically so that at any given time its activities are best given a genealogical explanation rather than one which is merely synchronic. Practices generate their own contexts - this implies that it is mistaken to try and explain, say, the rise of Impressionism through an analysis of social and economic conditions of the mid-19 $9^{\text {th }}$-century France; what those artists themselves thought and believed is far more important since they themselves were responding to a tradition of which they were a part.

All these considerations, it seems to me, can serve to keep the depredations of rationalisation at bay and to diminish its effects. Decisions to interpret internal goods through the lens of rationalisation may of course be made and often are: but they are deliberate decisions that can be contested through the invocation of the claims of the internal goods of that practice. But there are problems, all the same.

First, practices will often require some kind of institutional setting (subject disciplines in universities are a good example) and so the inevitable question arises as to what and to what extent the practice owes the institution that enables it to thrive in the first place. Institutional demands on practices that derive from the demands of rationalisation (for example, demands that are seen as manager-driven) may be impossible to resist. The second is that tightly drawn, compact practices may flourish much better than those which are much more porous and widely deployed. Tighter practices bind practitioners together and reduce the number of contestable aims and methods; looser practices are likely to contain far more contestable aims.

Politics, if it can be viewed as a practice at all, is of the latter kind. For there would appear to be no easy identification of political discourse that all can 
share and recognise: the only practice that all can share and recognise is that of rationalisation itself. Hence political discourse is translated into disputes about service provision and household management. The very identity of political subjects is itself rationalised so that such subjects require, for example, personal health analysis or educational performance in the form of learning targets and employability objectives. They need to be told how much alcohol they must drink and what to eat.

The recovery of political discourse, I suggest, must involve the recovery of political traditions the connection with which rationalisation has severed. This recovery also requires the re-birth of the political actor, viewed as an agent who is not subject to needs analysis and service provision but who is viewed as self-directed. I suggest that political discourse needs to centre on the issue of liberty, viewing agents as bearers of liberty, as liberty-bearing. Whatever identity an agent my have - ethnic, gender-based, cultural - their identity as a liberty-bearing actor does not change. In this way a political discourse can be forged that reaches back to the French Revolution, to the English civil war in the seventeenth century, to the practice of politics in Renaissance Florence, back to Roman antiquity. And it seems to me that once liberty is made into a central concern, there can also be constructed a legitimate area of debate in which the answers cannot be foreclosed in advance.

The first concerns the extent to which I am free in the sense that I am not interfered with. Given that all actors have similar claims to non-interference from each other what exactly constitutes interference and, in particular, what constitutes harmful interference. ${ }^{5}$ In particular, from the standpoint of liberty in this historic sense, a regime of rationalisation may be seen as sophisticated forms of interference. This would mean that a narrative of liberty which challenges and undermines rationalisation could be developed. If rationalisation constitutes one tradition of modernity then other traditions can be drawn on. But I would emphasise that the concept of liberty that needs to be employed in this respect is republican liberty, which emphasises the fact that I am only free to the extent that I am not dominated. This then leads into a second area of debate: to what extent should I be protected from domination? If liberty is construed in terms of non-domination, ${ }^{6}$ is all domination illegitimate? To

5 I still think the best arguments for so-called "negative liberty" are to be found in Isaiah Berlin's ideas - see Berlin, 1969.

6 The best modern account of liberty as non-domination - republican liberty is by Quentin Skinner (1998, 2002). 
what extent should the state foster arrangements whereby individuals develop resistance to domination and thus preserve their liberty? What collective arrangements of governance are needed to uphold liberty in the face of dominance and what kinds of domination are there?

Whilst I do not believe that all political questions can be re-interpreted in terms of liberty it does seem to me that many questions of justice and entitlement can be re-framed as questions of liberty - whether these questions be ones of welfare, education, health or public safety. In doing this we may be able to reconstruct political discourse in which the terms of rationalisation are subordinate to the internal goods of political practice. And the most prized of these goods is, I suggest, that of liberty. But once we see liberty as a concept with a historical tradition then we may be able to construct a "modern humanism" that has liberty at its heart. Humanism tends to be discredited because, I think, it has been colonised by rationalisation. Our humanism is reflected in the way that individual subjects are constructed as passive, as the receivers of services. But a more robust humanism would emphasise the subject as actor - not always victorious, but always as a self-directed agent for whom politics is an activity that involves actors.

The three vignettes are examples from the twentieth century in which political identity is discussed. In each case, the kind of political identity is questioning, restless but confident. In the first vignette we have a succinct probing of racism in which there is no resolution; in the second the claims of a hybrid political identity are asserted; and the third explores how the identity - i.e. the liberty - of others is systematically denied. All of them address issues of politics but they originate from outside the discourse of politics as such - from literature, poetry and philosophy. Thus to find out what remains of politics implies we may, in part, have to go outside politics; politics itself does not provide the answers it needs nor it is able to frame some of the questions.

\section{Vignettes of modern humanism}

\section{Leo Proudhammer}

Leo Proudhammer is the central protagonist in James Baldwin's Tell me how long the Train's Been Gone, published in 1968. He grows up in Harlem, New York and experiences at first hand the racism of white policeman and 
the patronisation of white liberals. But he also experiences freedom - sexual freedom (he is bisexual), a degree of artistic freedom (he is a struggling actor who manages to establish a professional reputation). He also experiences the camaraderie of living with similar young persons with no money but also with no responsibilities either. Leo doesn't always behave well (he flees the well-meaning but slightly clingy Madeleine for the much tougher Barbara) but on the other hand he doesn't try and find excuses for himself either. Above all, he is subject to racism, he is never simply a victim of racism. Here we have him and his brother conversing, having been stopped by a disagreeable New York cop:

"Caleb," I asked, "are white people - people?"

"What are you talking about, Leo?"

"I mean - are white people - people? People like us."

He looked down at me. His face was very strange and sad. It was a face I had never seen before. We climbed a few more stairs, very slowly. Then, "All I can tell you, Leo is - well, they don't think they are."

Julian Tuwim (1894-1953) an excerpt from We Polish Jews... (1944)

I am a Pole, because it pleases me. It is my personal and private matter, and I do not intend to submit a report nor an explication, an explanation to justify the basis of it. I do not divide Poles into "native- born" and "non-native-born"; I leave that for the native-born and non-native-born racists, the local and non-local Hitlerites. I divide Poles and Jews, as well all other nations, into intelligent and stupid, honest and thieves, intelligent and dullards, interesting and boring, the oppressing and the oppressed, gentlemanly and the ungentlemanly. I also divide Poles into fascists and anti-fascists. These two camps, are not, of course homogenous, each of them disperses shades of colour of differing intensities. But, the line of demarcation most certainly exists and shortly will be clearly seen. Shades will remain shades but the colour of that very line will be intense and deeper in a marked way.

I could say that in a political sense I divide Poles into anti-Semites and anti-Fascists. Because Fascism is always anti-Semitism. Anti-Semitism is the international language of Fascists. 


\title{
Jean-Paul Sartre (1905-1980) an excerpt from Anti-Semite and Jew (1944)
}

\begin{abstract}
The anti-Semite has chosen hate because hate is a faith; at the outset he has chosen to devaluate words and reasons. How entirely at ease he feels as a result. How futile and frivolous discussions about the rights of the Jew appear to him. He has placed himself on other ground from the beginning. If out of courtesy he consents for a moment to defend his point of view, he lends himself but does not give himself. He tries simply to project his intuitive certainty onto the plane of discourse. I mentioned awhile back some remarks by anti-Semites, all of them absurd: "I hate Jews because they make servants insubordinate, because a Jewish furrier robbed me, etc." Never believe that anti-Semites are completely unaware of the absurdity of their replies. They know that their remarks are frivolous, open to challenge. But they are amusing themselves, for it is their adversary who is obliged to use words responsibly, since he believes in words. The anti-Semites have the right to play. They even like to play with discourse for, by giving ridiculous reasons, they discredit the seriousness of their interlocutors. They delight in acting in bad faith.
\end{abstract}

\section{References}

Baldwin, J., Tell me how long the Train's Been Gone, Corgi Books, 1970.

Berlin, I., Four Essays on Liberty, Oxford: Oxford University Press, 1969.

Biggs, J. \& Tang, C., Teaching for Quality Learning at University, Open University Press, 2011.

Deleuze, G., October, Vol. 59, Winter, 1992, 3-7.

Habermas, J., The Theory of Communicative Action, Vol 1, Cambridge: Polity Press, 1991.

MacIntyre, A., After Virtue, London: Duckworth, 1981.

Rasmussen, D., Reading Habermas, Oxford: Basil Blackwell, 1990.

Sica, A., Rationalisation and Culture in Turner, 42-58, 2000.

Skinner, Q., Liberty before Liberalism, Cambridge: Cambridge University Press, 1998.

Skinner, Q., "A Third Concept of Liberty," Proceedings of the British Academy 117, 2002, 237-68.

Turner, S., The Cambridge Companion to Weber, Cambridge University Press, 2000.

Weber, M., The Protestant Ethic and the Spirit of Capitalism, London: George Allen and Unwin Ltd., 1930. 